\title{
The effects of palm vitamin E on stress hormone levels and gastric lesions in stress-induced rats
}

Ibrahim Abdel Aziz Ibrahim¹, Yusof Kamisah², Mohd Ismail Nafeeza', Mohd Fahami Nur Azlina²

1Department of Pharmacology, Faculty of Medicine, Universiti Teknologi MARA, Shah Alam, Selangor, Malaysia

2Department of Pharmacology, Faculty of Medicine, Universiti Kebangsaan Malaysia, Kuala Lumpur, Malaysia

Submitted: 18 August 2010

Accepted: 9 November 2010

Arch Med Sci 2012; 8, 1: 22-29

DOI: 10.5114 /aoms.2012.27276

Copyright $\odot 2012$ Termedia \& Banach

\section{Abstract}

Introduction: This study examines the effects of palm vitamin E (PVE) or $\alpha$-tocopherol ( $\alpha$-TF) supplementation on adrenocorticotropin hormone (ACTH), corticosterone and gastric lesions in rats exposed to water-immersion restraint stress (WIRS).

Material and methods: Sixty male Sprague-Dawley rats (200-250 g) were divided into three groups. Group I: 20 rats as a control group were given a normal diet. Group II: 20 rats received oral supplementation of PVE at $60 \mathrm{mg} / \mathrm{kg}$ body weight. Group III: 20 rats received oral supplementation of $\alpha$-TF at $60 \mathrm{mg} / \mathrm{kg}$ body weight. After the treatment period of 28 days, each group was further subdivided into two groups: 10 rats not exposed to stress, and the other 10 rats subjected to WIRS for $3.5 \mathrm{~h}$. Blood samples were taken to measure the ACTH and corticosterone levels. The rats were then sacrificed and the stomach excised and opened along the greater curvature and examined for lesions.

Results: Rats exposed to WIRS had lesions in their stomach mucosa. Our findings showed that dietary supplementation of PVE or $\alpha$-TF was able to reduce gastric lesions significantly in comparison to the stressed controls. The WIRS increased plasma ACTH and corticosterone significantly. Palm vitamin E and $\alpha$-TF treatments reduced these parameters significantly compared to the stressed controls.

Conclusions: Supplementation with either PVE or $\alpha$-TF reduces the formation of gastric lesions, probably by inhibiting the elevation of ACTH and corticosterone levels induced by stress.

Key words: palm vitamin $\mathrm{E}, \boldsymbol{\alpha}$-tocopherol, water-immersion restraint stress, adrenocorticotropic hormone, corticosterone, gastric lesions.

\section{Introduction}

Pathological changes caused by stress may affect organism psychological and physiological balances. Rats have been widely used in stress studies. There is an established model for producing gastric lesions by various methods of stress, such as restraint [1,2], water-immersion restraint [3] and cold-restraint stress [4].

The pathological basis for the development of gastric lesions is multifactorial. It includes factors which disrupt gastric mucosal integrity, such as changes in gastric acid, mucus and bicarbonate secretions, inhibition

\author{
Corresponding author: \\ Dr. Nur Azlina Mohd Fahami \\ Department of Pharmacology \\ Faculty of Medicine \\ Universiti Kebangsaan \\ Malaysia \\ Jalan Raja Muda Abdul Aziz \\ Kuala Lumpur, Malaysia \\ Phone: +6-03-92897507 \\ Fax: +6-03-26938205 \\ E-mail: \\ nazlina@medic.ukm.my
}


of gastric mucosal prostaglandin synthesis, reduction of gastric mucosal blood flow $[5,6]$ as well as changes in stress hormones $[1,3,7,8]$ and gastric motility $[9,10]$.

The plasma corticosterone level is the most striking hormonal change found in stress and is used as a sensitive index of stress [1]. On the other hand, the increase in corticosterone levels is a well-known physiological response to stress and is mediated by increased secretion of corticotrophin releasing hormone ( $\mathrm{CRH}$ ) by the hypothalamus, and adrenocorticotropic hormone (ACTH) as well as endorphins by the pituitary [11]. Nur Azlina and Nafeeza confirmed that an increase in the corticosterone level was correlated with the increased incidence of gastric lesions as seen in the stressed control rats. Thus, the corticosterone rise during stress was considered as an ulcerogenic factor. They also showed that tocotrienol and tocopherol were able to maintain the corticosterone level at the pre-stress values [8].

Vitamin $\mathrm{E}$ is a popular and powerful antioxidant which is effective in preventing oxidation of polyunsaturated fatty acids [12]. It is a fat-soluble vitamin, divided into two subgroups: tocopherols and tocotrienols. Tocopherol is known to be the most abundant and active form of vitamin $E$ homologues in vivo, but recently the role of other forms of vitamin $E$ has received renewed attention [13].

Based on findings from previous studies, it is of interest to investigate the effect of vitamin $E$ on $\mathrm{ACTH}$, in order to establish whether the effect of vitamin $\mathrm{E}$ on stress is directly through reduction of corticosterone or if vitamin E acts at a higher level by inhibiting ACTH.

Thus, the present study was designed to complete the previous study done by members of our research team Nur Azlina and Nafeeza, using the water-immersion restraint stress (WIRS) model because it induced acute gastric injury with a reliable reproducibility of gastric lesions. Additionally, we tried to establish the effects of palm vitamin $E$ (PVE) and $\alpha$-tocopherol ( $\alpha$-TF) supplements on gastric lesions, ACTH and corticosterone levels in rats exposed to WIRS.

\section{Material and methods}

Sixty male Sprague-Dawley rats (200-250 g) were divided into three equal-sized groups. Groups 1 (20 rats) and 2 (20 rats) were given PVE or $\alpha$-TF at the dose of $60 \mathrm{mg} / \mathrm{kg}$ body weight orally for 28 days, while the control group was given olive oil, which is the edible oil with the lowest content of vitamin $\mathrm{E}$, by using a 5 -inch, $21 \mathrm{G}$ needle, as vehicle [14]. At the end of the treatment period, blood was withdrawn from the orbital sinus using a capillary tube and each group was subdivided into another two groups; one group (10 rats) was subjected to waterimmersion restraint stress (WIRS) for $3.5 \mathrm{~h}$ and the other group (10 rats) was not subjected to any stress (non-stress group). All rats were kept on a regular night/day cycle, with natural light for a period of $10 \mathrm{~h}$ (700 to $1700 \mathrm{~h}$ ). Throughout the feeding period all rats were habituated to handling to reduce their stress-related disturbances. The rats were housed in large cages with wide wire-mesh bottoms to prevent coprophagy. Food and water were given ad libitum throughout the experiment. The rats were deprived of food overnight before they were exposed to stress.

Water-immersion restraint stress was conducted by placing each rat in a plastic restrainer individually, after which they were immersed neck-deep in a water bath at room temperature $\left(23^{\circ} \mathrm{C}\right)$ for $3.5 \mathrm{~h}$. This procedure was done according to the method previously described by Nishida et al. [15]. After exposure to stress, the rats were anaesthetized by injecting both ketamine ( $5 \mathrm{mg} / 100 \mathrm{~g}$ body weight) and xylazine (1 mg/100 g body weight) before blood sampling for biochemical determinations. The rats were then killed, after which the stomach was removed and examined for gastric lesions. The use of animals in this study was approved by Universiti Kebangsaan Malaysia Animal Ethics Committee (UKMAEC).

\section{Assessment of gastric lesions}

The gastric lesion area was measured under the microscope at the magnification of $3 \times$. Lesion size in $\mathrm{mm}$ was determined by measuring each lesion along its greatest diameter. Each five petechiae lesion was set as equivalent to $1 \mathrm{~mm}$ lesion. The total lengths in each group of rats were averaged and expressed as the lesion index. This method was previously described by Wong et al. [16].

\section{Plasma corticosterone level}

\section{Extraction of plasma corticosterone}

Plasma corticosterone was extracted according to a method described by Hofreiter et al. [17]. A sample of $100 \mu \mathrm{l}$ was thawed and added to $1 \mathrm{ml}$ dichloromethane in a $5-\mathrm{ml}$ plastic tube and was shaken for $10 \mathrm{~min}$. The mixture was then centrifuged at $1000 \mathrm{~g}$ for $5 \mathrm{~min}$ at $28^{\circ} \mathrm{C}$. The supernatant was removed and $\mathrm{NaOH}(0.05 \mathrm{M})$ was added later to wash the lower organic layer. The organic layer was re-centrifuged at $1000 \mathrm{~g}$ in order to separate any remaining aqueous component from the organic component. This process was repeated twice. A volume of $600 \mu \mathrm{l}$ from the lower layer (dichloromethane containing corticosterone) was pipetted into a new $10-\mathrm{ml}$ tube and dried. The drying extraction was carried out with concentrated vacuum for $30 \mathrm{~min}$ at a temperature of $-100^{\circ} \mathrm{C}$. The dried samples were kept at a temperature of $-20^{\circ} \mathrm{C}$ until analysed. 


\section{Preparation of standard solution} of corticosterone

Stock solution was prepared by mixing $1 \mathrm{mg}$ standard into $1 \mathrm{ml}$ methanol 60\% (without gas and HPLC grade) which contains 25 ng cortexolone as an internal standard. A series of liquefactions was carried out to obtain 10, 5, 2.5, 1.25, 0.5, 0.25 and $0.125 \mu \mathrm{g} / \mathrm{ml}$. The solution series was injected into a chromatography system for the purpose of calibration before sample analysis was performed.

\section{Determination of plasma corticosterone level}

The plasma corticosterone level was determined using a high performance liquid chromatography system (HPLC) (Waters Corp., Milford MA, USA) with ultraviolet detector (Waters Corp., Milford MA, USA) at wavelength of $240 \mathrm{~nm}$. The mobile phase solution was prepared through mixture of methanol and distilled water with a ratio of $60: 40$. The type of column was from $\mathrm{C}_{18}$, which was suitable for separating an organic substance like corticosterone.

A series of standard solutions was injected earlier into the system in order from the lowest to the highest concentration. The sample was analysed when the standard curve obtained a regression line close to one $(r>0.999)$. The plastic tube containing the dried sample extract was reconstituted with $1000 \mathrm{ml}$ of degassed methanol $60 \%$ which contained 25 ng cortexolone (internal standard), after which the reconstituted sample was filtered through a micro filter $(0.45 \mu \mathrm{m})$ (Nylon, Whatman). Filtered samples $(20-\mu \mathrm{m})$ were injected into the HPLC system. The flow rate of the mobile phase solution was $1.0 \mathrm{ml} / \mathrm{min}$.

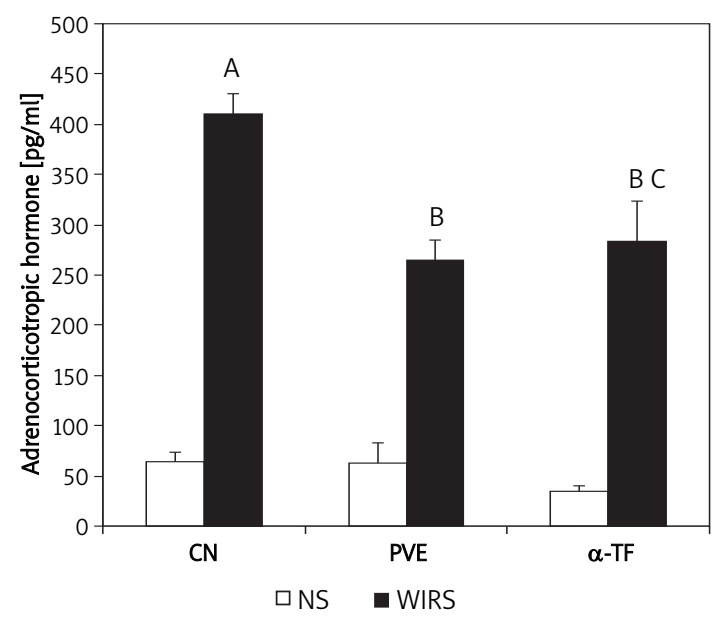

Figure 1. Effects of palm vitamin E (PVE) and $\alpha$-tocopherol $(\alpha-T F)$ on plasma adrenocorticotropic hormone $(A C T H)$ level in rats exposed to water-immersion restraint stress (WIRS). Each bar represents mean $\pm \operatorname{SEM}(n=10)$ : A vs. non-stressed group $(\mathrm{CN}+\mathrm{NS})(p<0.05)$, B vs. stressed control (CN + WIRS) $(p<0.05), C$ vs. non-stressed group respectively $(p<0.05)$

$\mathrm{CN}$ - control

\section{Determination of plasma adrenocorticotropic} hormone

Plasma adrenocorticotropic hormone level was determined in duplicate by a solid-phase, two-site sequential chemiluminescent immunometric assay (Immulite $1000^{\circledR}$, Siemens Medical Solutions Diagnostics, Los Angeles, USA) method using an IMMULITE automatic analyser (DPC, Los Angeles, CA). The principle of the assay was based on a chemiluminescent assay wherein alkaline phosphatase (bovine calf intestine) conjugated to polyclonal rabbit anti-ACTH antibody in buffer with sodium azide as preservative was used against $75 \mu \mathrm{l}$ of EDTA plasma samples containing ACTH. The plasma samples were pre-treated with the chemiluminescent substrate. The chemiluminescent substrate, a phosphate ester of adamantyl dioxetane, underwent hydrolysis in the presence of alkaline phosphatase to yield an unstable intermediate. The continuous production of these intermediates resulted in the sustained emission of light.

\section{Statistical analysis}

Statistical analysis was carried out using the SPSS statistical package version 12 (SPSS Inc. USA). Normal distribution of all variables was examined by the Kolmogorov-Smirnov test. The results are expressed as mean \pm SEM. Statistical significance $(p<0.05)$ was determined by ANOVA and Tukey's post-hoc test.

\section{Results}

\section{Effect of palm vitamin $E$ and $\boldsymbol{\alpha}$-tocopherol on plasma adrenocorticotropic hormone}

The plasma adrenocorticotropic hormone (ACTH) levels between the non-stressed groups were comparable (Figure 1). The exposure to water-immersion restraint stress (WIRS) for $3.5 \mathrm{~h}$ increased plasma ACTH level significantly (about $84.2 \%, p=0.001$ ) compared to the non-stressed control group. The WIRS also increased plasma ACTH level significantly in both PVE $(p=0.004)$ and $\alpha$-TF stressed groups ( $p=0.001$ ) compared to the non-stressed groups. The ACTH levels of stressed PVE (about 35.3\%, $p=0.007$ ) and $\alpha$-TF groups (about 30.9\%, $p=0.015$ ) were significantly lower compared to the stressed control group. However, no significant difference in the ACTH level between the stressed PVE and $\alpha$-TF groups was seen.

\section{Effect of palm vitamin $E$ and $\boldsymbol{\alpha}$-tocopherol on plasma corticosterone}

Figure 2 shows that the WIRS for $3.5 \mathrm{~h}$ increased the plasma corticosterone level significantly (about $32 \%, p=0.007$ ) compared to the non-stressed con- 
trol group. The WIRS also increased the plasma corticosterone level significantly in the PVE stressed group ( $p=0.003$ ) compared to the non-stressed group. However, no significant increase was seen in the $\alpha$-TF stressed group compared to the nonstressed group. The corticosterone levels of PVE$(p=0.008)$ and $\alpha$-TF- $(p=0.001)$ stressed groups were reduced significantly compared to the stressed control. There was no significant difference in the corticosterone level between the PVE and $\alpha$-TF nonstressed groups, and between the PVE and $\alpha-T F$ stressed groups.

\section{Effect of palm vitamin $E$ and $\alpha$-tocopherol on gastric lesions}

Non-stressed rats showed no focal lesions in the gastric mucosa. However, gastric mucosal lesions developed in rats subjected to WIRS for $3.5 \mathrm{~h}$. Macroscopic observation showed lesions, most often 1-2 mm in size, or petechial bleeding. The area of involvement was confined to the glandular part of the stomach. Pre-treatments with PVE reduced gastric lesions significantly by $52 \%(p=0.001)$ and $\alpha$-TF by $40 \%$ ( $p=0.001)$ in rats exposed to stress. In addition, the gastric lining illustrates the markedly reduced formation of gastric haemorrhagic lesions by supplements of $60 \mathrm{mg} / \mathrm{kg}$ of PVE and $\alpha$-TF for 28 days. The gastric lesion index was similar in the PVE and the $\alpha$-TF stressed groups, as shown in Figure 3.

\section{Discussion}

Stress has been shown to have deleterious effects on health. Many of these adverse effects are mediated through hormones that are released during stress. We found that the WIRS model used in this study caused a remarkable increase in plasma $\mathrm{ACTH}$ and corticosterone levels. These findings are in agreement with previous studies. Klenerová et al. and Lou et al. found that the plasma ACTH and corticosterone levels were elevated in rats exposed to WIRS $[18,19]$. Other studies using different models of stress, such as restraint or cold restraint stress, also demonstrated a similar finding, i.e. a rise in these stress hormones $[1,3,7,8]$.

It has been demonstrated that stress induces activation of the hypothalamus-pituitary-adrenal (HPA) axis [20]. When exposed to stress, the first system to respond is the autonomic nervous system, which sends a message to the hypothalamus. The hypothalamus, in turn, releases corticotropinreleasing factor (CRF), which is picked up by the nearby pituitary. This neuropeptide stimulates the pituitary to release ACTH into the bloodstream. The ACTH stimulates the production and release of glucocorticoids (corticosterone in rats, cortisol in humans) from the adrenal glands. Corticosterone

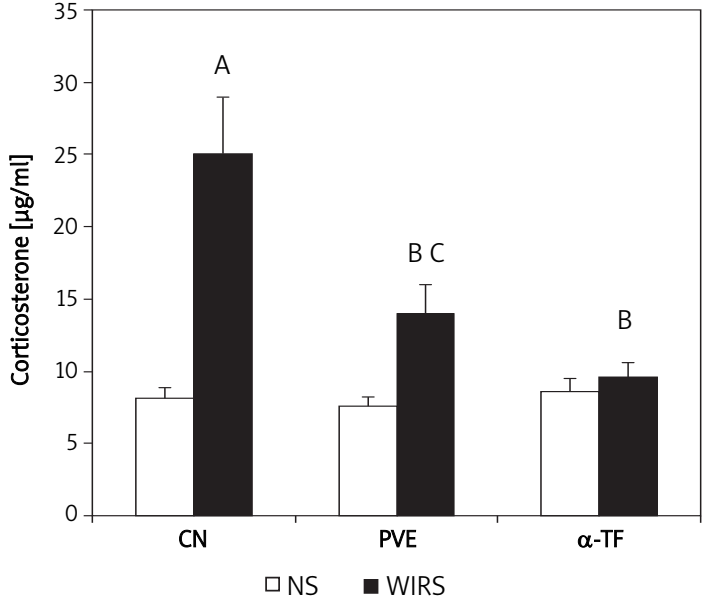

Figure 2. Effects of palm vitamin E (PVE) and $\alpha$-tocopherol $(\alpha-\mathrm{TF})$ on plasma corticosterone level in rats exposed to water-immersion restraint stress (WIRS). Each bar represents mean $\pm \operatorname{SEM}(n=10)$ : A vs. nonstressed group (CN + NS) $(p<0.05)$, B vs. stressed control (CN + WIRS) $(p<0.05)$, C vs. non-stressed group (PVE + NS) $(p<0.05)$

$\mathrm{CN}$ - control

stimulates the release of glucose from body stores, which provides energy to the body to fight off the danger or to run away from it. Once the threat is over, the mediators return to baseline levels due to negative feedback on the HPA axis [21, 22].

Corticosteroids are known to be a sensitive marker of the degree of stress experienced by an animal [23]. The elevation of plasma corticosterone in stressed rats noted in the present study is in agreement with the results of al-Shabanah et al., Ainsah et al., Klenerová et al., Lou et al. and Nur Azlina and Nafeeza [1, 8, 18, 19, 24]. This elevation could be explained on the basis that stress induces the

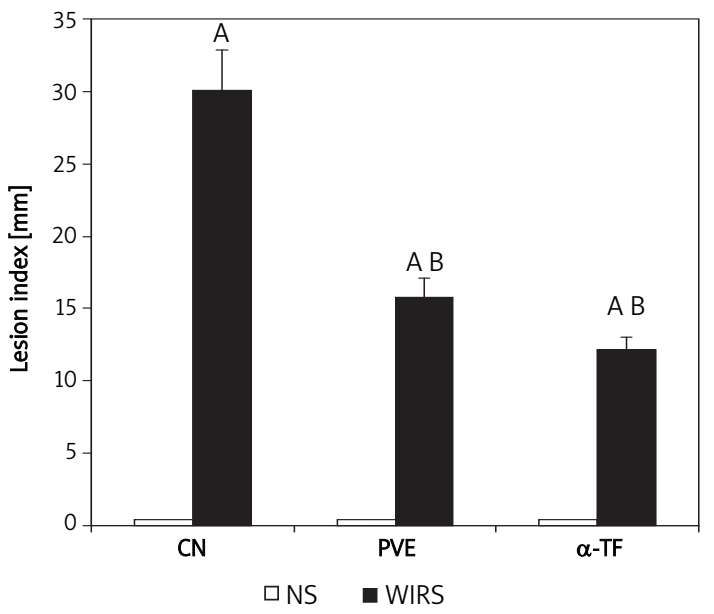

Figure 3. Effects of palm vitamin E (PVE) and $\alpha$-tocopherol $(\alpha$-TF) pre-treatments for 28 days on gastric lesions in rats exposed to water-immersion restraint stress (WIRS). Each bar represents mean \pm SEM $(n=10)$ : A vs. non-stressed group (NS) respectively $(p<0.05)$, B vs. stressed control (CN + WIRS) $(p<0.05)$ $\mathrm{CN}$ - control 
activation of the HPA axis causing increased secretion of pituitary endorphins, ACTH and adrenal corticosteroids such as corticosterone.

Hellhammer et al. reported that plasma levels of corticosterone were greatly increased by stress in both the lesion and the non-lesion groups compared to the home cage controls [25]. Further support for this idea came from the observation that animals with hippocampal lesions exhibit increased plasma corticosterone levels and develop more gastric erosions during stress [26].

Nur Azlina and Nafeeza confirmed that the increased corticosterone level correlated with increased incidence of gastric lesions as seen in the untreated stressed rats [8]. Thus, the corticosterone rise during stress was considered as an ulcerogenic factor. However, Murison et al. observed that metyrapone treatment reduced corticosterone levels under stress, but had no effect on lesion development [27]. Bakker and Murison studied the administration of corticotropin-releasing factor (CRF) to rats aged 100-220 days and then exposed to WIRS. The age of the animals itself was not a significant factor for either basal levels of plasma corticosterone or for the extent of restraint-induced gastric lesions. However, after CRF administration, only the young animals had a significant increase in plasma corticosterone levels, and post-restraint gastric ulcerations were more severe in older rats. The increased corticosterone secretion during stress is related to the increased occurrence of gastric lesions but it is not the sole causative agent for the pathogenesis of gastric lesions [28]. However, this suggests a new role of corticosterone produced during stress in gastric ulceration. Filaretova demonstrated that an acute rise of corticosterone during stress increased the resistance of the stomach to stress injury [29]. However, it is difficult to relate the increased corticosteroid secretion to stressinduced lesion formation because adrenalectomy has been reported to either increase [30] or inhibit [31] the production of stress-induced lesions.

In a study by Shaheen et al., intraperitoneal injection of $5 \mathrm{mg} / \mathrm{kg}$ body weight vitamin $\mathrm{E}$ for 6 days in rats prior to a single swimming test diminished the stress-induced elevation of corticosterone [32]. Ainsah et al. reported that compared to controls rats, rats treated with 90 or $150 \mathrm{mg}$ vitamin $\mathrm{E} / \mathrm{kg}$ rat chow for 8 weeks had significantly reduced plasma corticosterone, which accompanied an improvement in rats' locomotor activity. This reflected that vitamin $\mathrm{E}$ was able to inhibit stress-induced release of corticosterone and stress-induced psychomotor retardation, which may or may not be interdependent [1].

The synthesis of corticosterone in the adrenal gland requires free cholesterol. Taniguchi et al. showed that vitamin $\mathrm{E}$ reduced the conversion of cholesterol ester to free cholesterol. The reduced availability of free cholesterol subsequently caused a reduction in corticosterone synthesis [33].

Nur Azlina and Nafeeza reported that tocotrienol (TT) and tocopherol (TF) were capable of reducing the plasma corticosterone level in the condition of restraint stress [8]. Nevertheless, in the present study, the exposure to WIRS for $3.5 \mathrm{~h}$ increased the plasma corticosterone level significantly in the PVE stressed group but not in the $\alpha$-TF stressed group in comparison to the PVE non-stressed and $\alpha$-TF non-stressed groups respectively. This indicates that $\alpha$-TF has the ability to maintain the corticosterone level towards the normal non-stress level in stress conditions while PVE does not. However, the exposure to WIRS for $3.5 \mathrm{~h}$ increased the plasma ACTH level significantly in both PVE and $\alpha$-TF stressed groups compared to the non-stressed group. The reason for this discrepancy is unclear. It is possible that the high tocotrienol component in PVE is not as potent as tocopherol in inhibiting the conversion of cholesterol ester to free cholesterol; this hypothesis needs to be further investigated. The other reason could be related to the duration of stress and the different models of stress used in the Nur Azlina and Nafeeza study. It is well known that restraint stress alone is a milder stress model, which was shown by an increase of corticosterone by only $18.6 \%$ [8], but in this study it was found that the effect of WIRS induced a critical increase in corticosterone of $32 \%$, and this demonstrates the difference between the two stress models.

The ability to reduce the stress-induced increase in corticosterone level by PVE in acute and more extensive stress may be lower. Thus, it is possible that a higher dose of PVE is needed to achieve an effect similar to treatment with $\alpha$-TF alone. In the study by Nur Azlina and Nafeeza, there was no significant difference in plasma corticosterone levels between TT and $\alpha$-TF treated groups, pre- and poststressed [8]. Thus, treatment with both TT and $\alpha$-TF can block the increase in corticosterone levels due to stress. In their study, however, a pure dose of TT was used.

In other words, TT and TF $(60 \mathrm{mg} / \mathrm{kg}$ ) were able to reduce the corticosterone level [8]; however, the present study found that $\alpha-\operatorname{TF}(60 \mathrm{mg} / \mathrm{kg}$ ) was able to reduce corticosterone but not PVE $(60 \mathrm{mg} / \mathrm{kg})$, which is a mixture of TT (i.e. $<60 \mathrm{mg} / \mathrm{kg}$ ) and TF (i.e. $<60 \mathrm{mg} / \mathrm{kg}$ ). Therefore, TT and TF in combination are not effective in reducing corticosterone levels because sub-therapeutic doses of TT and TF were present in PVE and obviously combination does not have an additive effect. Alternatively, there is an apparent antagonism. This antagonism is more likely to occur beyond the pituitary because PVE is able to suppress the release of ACTH. It is possible that PVE or TT and TF in sub-therapeutic 
doses are not able to reduce the conversion of cholesterol ester to free cholesterol. Hence it is seen that the sub-therapeutic levels do not show significant reduction in the availability of free cholesterol.

Previous studies have demonstrated that gastric lesions can develop in experimental animals following psychological or physical stress [34, 35]. Gastric lesions caused by stress, alcohol, Helicobacter pylori infection and non-steroidal anti-inflammatory drugs have been shown to be mediated largely through the generation of reactive oxygen species (ROS) that seem to play an important role in producing lipid peroxides [35-38].

Rats have been widely used in stress studies. There are some established models for producing gastric lesions from various methods of stress. Nur Azlina et al. found that rats which were exposed to restraint stress for 2 h every day for 4 days developed lesions in their gastric glandular mucosa [35]. Singh et al. also reported that cold-restraint stress caused considerable ulceration in the form of haemorrhagic mucosal lesions in the stomach [39]. However, exposure to WIRS for $3.5 \mathrm{~h}$ resulted in the immediate appearance of multiple gastric lesions in the gastric mucosa [40].

As shown in this study, the animals exposed to water-immersion restraint stress for $3.5 \mathrm{~h}$ developed gastric mucosa lesions, thus confirming the reproducibility of this model for the study. The pathological basis for the development of these lesions is multifactorial [41, 42]. The formation of the gastric lesions might be due to increased gastric contractions, which resulted in temporary restriction of blood flow to the mucosa. This restriction of the blood flow might also involve vascular contraction or the shunting of blood away from the mucosa, thereby accentuating anoxic damage [43, 44]. Stress-induced strong vasoconstrictions of the gastric wall and compression of the intramural vessels are probably responsible for some degenerative changes in the mucosal cells, leading to impairment of the gastric microcirculation and, finally, gastric lesions [45].

The data of this study showed that vitamin $E$ supplementations (PVE or $\alpha$-TF) at the dose of $60 \mathrm{mg} / \mathrm{kg}$ body weight for 28 days was able to decrease stress effects (in this case gastric lesions) by reducing the plasma $\mathrm{ACTH}$ and corticosterone levels. Furthermore, supplementation of PVE and $\alpha$-TF at $60 \mathrm{mg} / \mathrm{kg}$ for 28 days prior to exposure to stress reduced gastric mucosal injury. This finding is similar to other studies [35, 46, 47]. Nur Azlina et al. showed that supplementation with TT and TF was able to reduce the formation of lesions in the gastric mucosa after restraint stress insult [35]. However, no difference between these two agents was observed, showing their equal effectiveness in preventing stress-induced gastric injury. The study by Kamsiah et al. examined the effects of various doses of PVE and TF on the prevention of aspirininduced gastric lesions. The gastric lesion index was found to be significantly lower in all the vitamin $\mathrm{E}$ groups compared to the control group, but there was no significant difference in ulcer indices between palm vitamin $\mathrm{E}$ and tocopherol-treated groups [46]. However, PVE administration in a dose of $100 \mathrm{mg} / \mathrm{kg}$ weight and $150 \mathrm{mg} / \mathrm{kg}$ body weight was more effective in preventing aspirin-induced gastric lesions than TF in a dose of $30 \mathrm{mg} / \mathrm{kg}$ weight, as the gastric mucosal thickness in these PVE groups was significantly higher compared to the other groups [48].

Similarly, exposure to WIRS has been shown to increase the incidence of gastric mucosal lesions and the increase was lowered by the administration of various antioxidants $[49,50]$. A study by Ohta et al. demonstrated that WIRS for $6 \mathrm{~h}$ reduced gastric $\alpha$-tocopherol concentration but pre-administration of ascorbic acid partially reversed this reduction. Hence, in the present study, the prevention of the harmful effects of the stress may be mediated by the antioxidant activity possessed by the PVE and $\alpha$-TF, by either directly or indirectly reducing the formation of free radicals which cause gastric lesions [35]. Furthermore, Brzozowski et al. confirmed that pre-treatment with grapefruit seed extract, which has antioxidative activity, applied topically in doses ranging from $8 \mathrm{mg} / \mathrm{kg}$ to $64 \mathrm{mg} / \mathrm{kg}$, caused a significant reduction in WIRS-induced gastric lesions [50].

The vitamin E protective mechanism and its role in human health are still not well understood. The characteristic of vitamin $\mathrm{E}$ as an antioxidant, especially its effect on polyunsaturated fatty acids (PUFA), may improve cell membrane integrity. It may cause gastric tissue to become more resistant to gastric aggressive factors such as acid and pepsin. The outcome of this study and previous studies suggests that vitamin $\mathrm{E}$ has a significant protective effect against stress-induced gastric lesions $[35,51]$. Based on this, there is a possibility that it could be used as a treatment for stressinduced gastric lesions.

In conclusion, our data suggest that exposure to WIRS for $3.5 \mathrm{~h}$ caused gastric lesion formation and elevated the stress hormones ACTH and corticosterone, and these increases were reduced by PVE and $\alpha$-TF. Supplementation with PVE or $\alpha$-TF was able to reduce the formation of gastric lesions significantly compared to the stress control group.

\section{Acknowledgments}

The study was funded by a grant from the Malaysian Ministry of Science, Technology, and Innovations (IRPA Grant No. 06-02-02-10026 EAR). 
The authors wish to thank Mrs Norhayati Mohd Yassin, Mrs. Azizah Othman and Mrs. Mazlidiyana Mazlan for technical assistance.

\section{References}

1. Ainsah O, Nabishah BM, Osman CB, Khalid BAK. Naloxone and vitamin $E$ block stress-induced reduction of locomotors activity and elevation of plasma corticosterone. Exp Clin Endocrinol Diabetes 1999; 107: 462-7.

2. Nur Azlina MF, Nafeeza MI. Phytonutrient: effects on lipid peroxidation in experimental gastritis induced by restraint stress. Int J Pharm 2007; 3: 254-9.

3. Filaretova L, Maltcev N, Bogdanov A, Levkovich Y. Role of gastric microcirculation in the gastroprotection by glucocorticoids released during water-restraint stress in rats. Chin J Physiol 1999; 42: 145-52.

4. al-Moutairy A, Tariq M. Effect of vitamin E and selenium on hypothermic restraint stress and chemically-induced ulcers. Dig Dis Sci 1996; 41: 1165-71.

5. Brzozowski T, Konturek PC, Sliwowski Z, et al. Prostaglandin/cyclooxygenase pathway in ghrelin-induced gastroprotectin against ischemia-reperfusion injury. J Pharmacol Exp Ther 2006; 319: 447-87.

6. Brzozowski T, Konturek PC, Sliwowski Z, et al. Gastroprotective action of orexin-A against stress-induced gastric damage is mediated by endogenous prostaglandins, sensory afferent neuropeptides and nitric oxide. Regul Pept 2008; 148: 6-20.

7. Dronjak S, Gavrilović L, Filipović D, Radojcić MB. Immobilization and cold stress affect sympathoadrenomedullary system and pituitary-adrenocortical axis of rats exposed to long-term isolation and crowding. Physiol Behav 2004; 81: 409-15.

8. Nur Azlina MF, Nafeeza MI. Tocotrienol and alphatocopherol reduce corticosterone and noradrenalin levels in rats exposed to restraint stress. Pharmazie 2008; 63: 890-2.

9. DuBay D, Ephgrave KS, Cullen JJ, Broadhurst KA. Intracerebroventricular calcitonin prevents stress-induced gastric dysfunction. J Surg Res 2003; 110: 188-92.

10. Ephgrave KS, Scott DL, Ong A, Cullen JJ, Broadhurst KA Are gastric, jejunal, or both forms of enteral feeding gastroprotective during stress? J Surg Res 2000; 88: 1-7.

11. Lim ATW, Funder JW. Stress-induced changes in plasma, pituitary and hypothalamic immunoreactive betaendorphin: effects of diurnal variation, adrenalectomy, corticosteroids, and opiate agonists and antagonists. Neuroendocrinology 1983; 36: 225-34.

12. Jialal I, Grundy SM. Effects of combined supplementation with alpha-tocopherol, ascorbate and beta-carotene on low-density lipoprotein oxidation. Circulation 1993; 88: 2780-6.

13. Yoshida Y, Niki E, Noguchi N. Comparative study on the action of tocopherols and tocotrienols as antioxidant: chemical and physical effects. Chem Phys Lipids 2003; 123: 63-75.

14. Cottrell RC. Introduction: nutritional aspects of palm oil. Am J Clin Nutr 1991; 53 (4 Suppl): 989S-1009S.

15. Nishida K, Ohta Y, Kobayashi T, Ishiguro I. Involvement of the xanthine-xanthine oxidase system and neutrophils in the development of acute gastric mucosal lesions in rats with water immersion restraint stress. Digestion 1997; 58: 340-51.

16. Wong D, Koo MW, Shin VY, Liu ES, Cho CH. Pathogenesis of nicotine treatment and its withdrawal on stress- induced gastric ulceration in rats. Eur J Phramacol 2002; 434: 81-6.

17. Hofreiter BT, Allen JP, Mizera AC, Powers CD, Masi AM. High-performance liquid chromatography and radioimmunoassay of rat plasma corticosterone. Steroids 1982; 39: 547-55.

18. Klenerová V, Jurcovicova J, Kaminsky O, et al. Combined restraint and cold stress in rats: effects on memory processing in passive avoidance task and on plasma levels of ACTH and corticosterone. Behav Brain Res 2003; 142: 143-9.

19. Lou LX, Geng B, Du JB, Tang CS. Hydrogen sulphideinduced hypothermia attenuates stress-related ulceration in rats. Clin Exp Pharmacol Phys 2008; 35: 223-8.

20. Stark R, Wolf OT, Tabbert K, et al. Influence of the stress hormone cortisol on fear conditioning in humans: evidence for sex differences in the response of the prefrontal cortex. Neuroimage 2006; 32: 1290-8.

21. McEwen BS. Mood disorders and allostatic load. Biol Psychiatry 2002; 54: 200-7.

22. Carrasco GA, Van de Kar LD. Neuroendocrine pharmacology of stress. Eur J Pharmacol 2003; 463: 235-72.

23. Kheir-Eldin AA, Motawi TK, Gad MZ, Abd-ElGawad HM. Protective effect of vitamin $\mathrm{E}$, beta-carotene and $\mathrm{N}$ acetylcysteine from the brain oxidative stress induced in rats by lipopolysaccharide. Int J Biochem Cell Biol 2001; 33: 475-82.

24. al-Shabanah OA, Mostafa YH, Hassan MT, Khairaldin AA, al-Sawaf HA. Vitamin $E$ protects against bacterial endotoxin-induced increase of plasma corticosterone and brain glutamate in the rat. Res Commun Mol Pathol Pharmacol 1996; 92: 95-105.

25. Hellhammer DH, Hingtgen JN, Wade SE, Shea PA, Aprison $\mathrm{MH}$. Serotonergic changes in specific areas of rat brain associated with activity: stress gastric lesions. Psychosom Med 1983; 45: 115-22.

26. Murphy HM, Wideman $\mathrm{CH}$, Brown TS. Plasma corticosterone levels and ulcer formation in rats with hippocampal lesions. Neuroendocrinology 1979; 28: 123-30.

27. Murison R, Overmier JB, Hellhammer DH, Carmona M. Hypothalamo-pituitary-adrenal manipulations and stress ulcerations in rats. Psychoneuroendocrinology 1989; 14: 331-8.

28. Bakker HK, Murison R. Plasma corticosterone and restraint induced gastric pathology: age-related differences after administration of corticotropin releasing factor. Life Sci 1989; 45: 907-16.

29. Filaretova L. The hypothalamic-pituitary-adrenocortical system: hormonal brain-gut interaction and gastroprotection. Auton Neurosci 2006; 125: 86-93.

30. Brodie DA, Hanson HM. A study of the factors involved in the production of gastric ulcers by the restraint technique. Gastroenterology 1960; 38: 353-60.

31. Sethbhadki S, Roth JLA, Pfeiffer CH. Gastric mucosal ulceration after epinephrine. A study of the etiologic mechanisms. Am J Dig Dis 1970; 15: 1055-65.

32. Shaheen AA, Hamdy MA, Kheir-Eldin AA, Lindström PEl, Fattah AA. Effect of pretreatment with vitamin $E$ or diazepam on brain metabolism of stressed rats. Biochem Pharmacol 1993; 46: 194-7.

33. Taniguchi N, Ohtsuka A, Hayashi $\mathrm{K}$ A high dose of vitamin E inhibits adrenal corticosterone synthesis in chickens treated with ACTH. J Nutr Sci Vitamol 2001; 47: 40-6.

34. Das D, Banerjee RK. Effect of stress on the antioxidant enzymes and gastric ulceration. Mol Cell Biochem 1993; 125: $115-25$ 
35. Nur Azlina MF, Nafeeza MI, Khalid BAK. Effect of tocotrienol on lipid peroxidation in experimental gastritis induced by restraint stress. Pak J Nutr 2005; 4: 69-72.

36. Brzozowski T, Konturek PC, Chlopicki S, et al. Therapeutic potential of 1-methylnicotinamide against acute gastric lesions induced by stress: role of endogenous prostacyclin and sensory nerves. J Pharmacol Exp Ther 2008; 326: 105-16.

37. Park SW, Oh TY, Kim YS, et al. Artemisia asiatica extracts protect against ethanol-induced injury in gastric mucosa of rats. J Gastroenterol Hepatol 2008; 23: 976-84.

38. Mita M, Satoh M, Shimada A, et al. Metallothionein is a crucial protective factor against Helicobacter pyloriinduced gastric erosive lesions in a mouse model. Am J Physiol Gastrointest Liver Physiol 2008; 294: G877-84.

39. Singh S, Khajuria A, Taneja SC, et al. The gastric ulcer protective effect of boswellic acids, a leukotriene inhibitor from Boswellia serrata, in rats. Phytomedicine 2008; 15 : 408-15.

40. Konturek PC, Brzozowski T, Dudab A, et al. Epidermal growth factor and prostaglandin E2 accelerate mucosal recovery from stress-induced gastric lesions via inhibition of apoptosis. J Physiol Paris 2001; 95: 361-7.

41. Güzel C, Kurt D, Sermet A, Kanay Z, Denli O, Canoruc F. The effects of vitamin $E$ on gastric ulcers and gastric mucosal barrier in stress induced rats. Turk J Med Sci 1998; 28: 19-21.

42. Önen A, Kanay Z, Güzel C, Kurt D, Ceylan K. The effects of allopurinol on stomach mucosal barrier of rats subjected to ischemia-reperfusion. Turk J Med Sci 2000; 30: 449-52.

43. Garrick T, Buack S, Bass P. Gastric motility is a major factor in cold restraint-induced lesion formation in rats. Am J Physiol 1986; 250: G191-9.

44. Ephgrave K, Brasel K, Cullen J, Broadhurst K. Gastric mucosal protection from enteral nutrients: role of motility. J Am Coll Surg 1998; 186: 434-40.

45. Konturek PC, Brzozowski T, Konturek SJ, et al. Activation of genes for growth factors and cyclooxygenase in rat gastric mucosa during recovery from stress damage. Eur J Pharmacol 1998; 342: 55-65.

46. Jaarin K, Gapor MT, Nafeeza MI, Fauzee AM. Effect of various doses of palm vitamin $E$ and tocopherol on aspirin-induced gastric lesions in rats. Int J Exp Pathol 2002; 83: 295-302.

47. Nafeeza MI, Fauzee AM, Kamsiah J, Gapor MT. Comparative effects of a tocotrienol-rich fraction and tocopherol in aspirin-induced gastric lesions in rats. Asia Pac J Clin Nutr 2002; 11: 309-13.

48. Kamsiah J, Muhaizan W, Gapor MT, Roslin O. Mucosal protective effects of vitamin $\mathrm{E}$ on aspirin-induced gastric lesions in rats. Int J Pharmacol 2005; 1: 93-7.

49. Ohta Y, Kamiya Y, Imai Y, Arisawa T, Nakano H. Role of gastric mucosal ascorbic acid in gastric mucosal lesion development in rats with water immersion restraint stress. Inflammopharmacology 2005; 13: 249-59.

50. Brzozowski T, Konturek PC, Drozdowicz D, et al. Grapefruitseed extract attenuates ethanol-and stress-induced gastric lesions via activation of prostaglandin, nitric oxide and sensory nerve pathways. World I Gastroenterol 2005; 11: 6450-8.

51. Ozdil S, Bolkent Ș, Yanardaq R, Arda-Pirincci P. Protective effects of ascorbic acid, DL-alpha-tocopherol acetate, and sodium selenate on ethanol-induced liver damage of rats. Biol Trace Elem Res 2004; 97: 149-62. 